Л.А. БАЛЫКОВА ${ }^{1}$, Д.М.Н., ПрОфесСор, С.В. ГАРИНА ${ }^{1}$, И.С. НАЗАРОВА ${ }^{1}$, Н.Р. БЕЛКИНА ${ }^{2}$, Я.Р. СЕРГЕЕВА ${ }^{1}$

${ }^{1}$ Национальный исследовательский Мордовский государственный университет им. Н.П. Огарева, Саранск

2 Детская республиканская клиническая больница РФ, Саранск

\title{
НОВЫЙ СПОСОБ
}



\begin{abstract}
Ранняя диагностика и своевременная коррекция патологических изменений со стороны сердца у новорожденных детей может стать важнейшим фактором в снижении частоты и тяжести кардиоваскулярной патологии у детей более старшего возраста и взрослых. Учитывая важную роль вторичного дефицита карнитина в развитии дезадаптационных кардиопатий у новорожденных (особенно недоношенных и незрелых), изучение эффективности экзогенного левокарнитина (L-карнитин) в неонатальной кардиологии является перспективным. Целью исследования была оценка эффективности раствора L-карнитин при постгипоксическом синдроме дезадаптации сердечно-сосудистой системы у новорожденных, в том числе недоношенных детей. После курса препарата показана эффективная редукция признаков электрической нестабильности и ишемии миокарда, восстановление чСС и нормализация систолической и диастолической функции сердца, размеров полостей сердца, уменьшение диаметра и гемодинамической значимости функционирующих фетальных коммуникаций, восстановление циркадной организации ритма сердца, а также сокращение длительности пауз ритма и представленности аритмий. Полученные результаты свидетельствуют об эффективности и безопасности раствора L-карнитин в коррекции кардиальных нарушений у новорожденных с гипоксическим повреждением миокарда.
\end{abstract}

Ключевые слова: новорожденные дети, постгипоксическая кардиопатия, L-карнитин, гипоксия.

\section{L.A. BALYKOVA ${ }^{1}$, MD, Prof., S.V. GARINA ${ }^{1}$, I.S. NAZAROVA ${ }^{1}$, N.R. BELKINA ${ }^{2}$, Ya.R. SERGEEVA ${ }^{1}$ \\ ${ }^{1}$ Ogarev Mordovia State National Research University \\ 2 Children Republican Clinical Hospital of the Russian Federation, Saransk}

NEW METHOD OF PHARMACOLOGICAL CORRECTION OF POST-HYPOXIC CARDIOPATHY IN NEWBORNS

Early diagnosis and timely correction of pathological changes in the newborns' heart can be a major factor in reducing the frequency and severity of cardiovascular pathology in older children and adults. Given the important role of secondary carnitine deficiency in developing disadaptant cardiopathies in newborns (especially premature and immature), the study of the efficacy of exogenous levocarnitine (L-carnitine) in neonatal cardiology offers the greatest promise. The study was aimed at evaluating the efficacy of L-carnitine solution in the post-hypoxic syndrome of cardiovascular deconditioning in newborns, including premature infants. After the treatment course, the newborns showed the effective reduction of signs of electrical instability and myocardial ischemia, restoration of heart rate and resetting of systolic and diastolic function of the heart, the size of the heart cavities, a decrease in the diameter and hemodynamic significance of functioning fetal communications, the restoration of the circadian heart rhythm profile, as well as a reduction in the duration of pauses in rhythm and arrhythmias. The study results showed the efficacy and safety of the L-carnitine solution in correcting cardiac disorders in newborns with hypoxic myocardial damage.

Keywords: newborns, post-hypoxic cardiopathy, L-carnitine, hypoxia.

охранение и укрепление здоровья детей является одной из первостепенных задач нашего государства. В условиях сложившейся неблагоприятной демографической ситуации и значительного ухудшения состояния здоровья женщин фертильного возраста особую актуальность приобретает сохранение жизни и здоровья каждого родившегося ребенка. Показатели младенческой и перинатальной смертности в течение последних лет являются довольно низкими, практически соответствующими уровню развитых европейских стран, однако общая заболеваемость детского населения неуклонно возрастает [1]. Происходит это преимущественно за счет последствий отдельных состояний перинатального периода, среди которых ведущую роль играет внутриутробная гипоксия и асфиксия при рождении. Комплекс изменений, возникающих при этом, оказывает неблагоприятное влияние как на центральную нерв- ную систему (ЦНС), нарушая регулирующее влияние подкорковых структур головного мозга на функциональное состояние внутренних органов, так и непосредственно на сердечно-сосудистую систему (ССС) [2]. Ранняя диагностика и своевременная коррекция патологических изменений со стороны сердца у новорожденных и детей первого года жизни может стать важнейшим фактором в снижении частоты и тяжести кардиоваскулярной патологии у детей более старшего возраста и взрослых [3].

Особенности строения кардиомиоцитов у новорожденного, ведущая роль углеводного обмена с быстрым истощением аэробного гликолиза определяют значительную роль гипоксии в генезе нарушений процессов адаптации ССС. В результате гипоксии у плода и новорожденного нарушается вегетативная регуляция сердца и сосудов, в том числе и коронарных. Возникающие нарушения вызывают изменения в энергетическом обмене миокар- 
да, приводя к быстрому снижению его сократительной функции [4]. Этому способствуют анатомо-физиологические особенности: рассыпной тип коронарных артерий, физиологическая карнитиновая недостаточность [5]. Результатом гипоксического повреждения миокарда является очаговая дистрофия, которая может иметь два варианта развития - полное восстановление функции либо формирование очагового кардиосклероза. Нарушения со стороны ССС, возникающие в неонатальном периоде и обусловленные гипоксическим воздействием, характеризуются значительным полиморфизмом и в целом объединены в понятие «синдром дезадаптации сердечно-сосудистой системы» (постгипоксическая кардиопатия) [6]. Предложено [3] выделять четыре клиникопатогенетических варианта постгипоксической кардиопатии: 1) неонатальная легочная гипертензия и персистирование фетальных коммуникаций (персистирующее фетальное кровообращение), 2) транзиторная дисфункция миокарда с дилатацией полостей, нормальной или повышенной сократительной способностью, 3) транзиторная дисфункция миокарда с дилатацией полостей и сниженной сократительной способностью, 4) нарушения ритма и проводимости.

В последнее время большое внимание в научной литературе уделяется вопросу кардиопротекции при ишемическом и стрессорном повреждении миокарда. Одним из путей оптимизации метаболизма сердечной мышцы в условиях ишемии и гипоксии является воздействие на процессы энергообеспечения [7]. Возможность медикаментозного влияния на биогенез митохондрий и поиск средств, препятствующих оксидативному стрессу, повышающих содержание аденозинтрифосфата (АТФ) в миокарде, весьма перспективны [8]. Основным источником энергии для миокарда являются свободные жирные кислоты, активация их окисления в условиях нетяжелой гипоксии будет давать максимальный энергетический эффект. Одним из веществ, участвующих в окислении свободных жирных кислот, является L-карнитин. При участии левокарнитина возможен транспорт длинноцепочечных жирных кислот через мембраны митохондрий, где происходит их окисление с образованием АТФ, связывание и удаление токсичных органических соединений, образующихся в результате окисления жирных кислот, процесс гликолиза, обмен кетоновых тел и холина [9]. У новорожденных, особенно недоношенных детей, способность к синтезу карнитина крайне ограниченна, причем на активность эндогенного образования влияет функциональное состояние внутренних органов. Период новорожденности отличается напряжением и дефицитом энергетического обмена в виде «функциональной» карнитиновой недостаточности [5, 10], выраженного снижения активности митохондриальных ферментов - сукцинат-, лактат-, глутаматдегидрогеназ (СДГ, ЛДГ, ГДГ) [7]. Нарушения энергетического обмена и карнитиновый дефицит значительно усугубляются в случае недоношенности, повреждения нервной системы, дыхательных расстройств и сердечно-сосудистой недостаточности, анемии и гипербилирубинемии $[11,12]$.
Одним из перспективных средств для коррекции дезадаптационных нарушений ССС у новорожденных являются препараты L-карнитина, пероральная форма которых давно и успешно используется в детской кардиологии, проявляя противоишемическое, антиоксидантное, положительное гемодинамическое действие, уменьшая явления электрической нестабильности миокарда и автономной дисфункции $[8,10]$. Однако с учетом фармакокинетики лекарственных средств у новорожденных оптимальная биодоступность препарата будет получена при внутривенном способе введения.

\section{Ранняя диагностика и своевременная коррекция патологических изменений со стороны сердча у новорожденных и детей первого года жизни может стать важнейшим фактором в снижении частоты и тяжести кардиоваскулярной патологии у детей более старшего возраста и взрослых}

Цель исследования: оценить эффективность и безопасность применения препарата L-карнитин (раствор для внутривенного и внутримышечного введения 100 мг/мл) в комплексном лечении новорожденных детей разного срока гестации с постгипоксической кардиопатией.

\section{ПАЦИЕНТЫ И МЕТОДЫ ИССЛЕДОВАНИЯ}

С одобрения Локального этического комитета при ФГБОУ ВО «МГУ им. Н.П. Огарева» (протокол №48 от 12.05.2015) проведено открытое простое сравнительное рандомизированное исследование препарата L-карнитин для коррекции признаков дезадаптационной (постгипоксической) кардиопатии у 83 доношенных и недоношенных новорожденных. Все дети находились на обследовании и лечении в отделении патологии новорожденных и недоношенных детей ГБУЗ РМ «ДРКБ» и нуждались в проведении инфузионной терапии в связи с основной и/или сопутствующей патологией (церебральная ишемия, гипербилирубинемия, гипотрофия, недоношенность и др.).

Критериями включения явилось наличие в анамнезе ребенка указаний на перенесенную перинатальную гипоксию с явлениями гипоксически-ишемического (или гипоксически-геморрагического для недоношенных) повреждения ЦНС по типу церебральной ишемии (ЦИ) и внутрижелудочковых кровоизлияний I-II ст. для недоношенных, а также постгипоксическими сердечно-сосудистыми нарушениями перинатального периода (код Р29 по МКБХ) или дезадаптационной кардиопатией по классификации Н.П. Котлуковой по данным объективного и/ или инструментального обследования (нарушение процессов реполяризации на ЭКГ, расстройство ритма и проводимости сердца, нарушение сократительной способности миокарда, дилатация полостей сердца, признаки легочной гипертензии) на 4-6-е сутки жизни.

Из исследования исключались дети с органической патологией ССС (врожденные пороки сердца, кардиты, кардиомиопатии) и нервной системы (врожденные поро- 
Таблица 1. Характеристика обследуемых детей

\begin{tabular}{|c|c|c|c|c|}
\hline \multirow{2}{*}{ Показатель } & \multicolumn{2}{|c|}{ Исследуемая группа ( $=$ = 43) } & \multirow{2}{*}{$\begin{array}{c}\text { Группа } \\
\text { сравнения } \\
(n=40)\end{array}$} & \multirow{2}{*}{$\begin{array}{c}\text { Контрольная } \\
\text { группа } \\
(n=20)\end{array}$} \\
\hline & $\begin{array}{c}\text { Подгруппа } 1 \\
(n=23)\end{array}$ & $\begin{array}{c}\text { Подгруппа } 2 \\
(n=20)\end{array}$ & & \\
\hline Срок гестации, M \pm m (нед.) & $36,2 \pm 0,59$ & $36,05 \pm 0,57$ & $37,3 \pm 0,85$ & $37,9 \pm 0,71$ \\
\hline Мальчики/девочки & $11 / 12$ & $10 / 10$ & $20 / 20$ & $11 / 9$ \\
\hline Масса при рождении, М \pm m (г) & $2480,5 \pm 124,2$ & $2486,7 \pm 130,9$ & $2500,1 \pm 71,6$ & $2710,2 \pm 82,5$ \\
\hline Оперативные роды, n (\%) & $12(52,1)$ & $10(50)$ & $16(40,0)$ & $6(30,0)$ \\
\hline $\begin{array}{c}\text { Оценка по Апгар, } \\
1 \text { мин, } \mathrm{M} \pm \mathrm{m} \\
5 \text { мин, } \mathrm{M} \pm \mathrm{m}\end{array}$ & $\begin{array}{l}6,9 \pm 0,11 \\
7,4 \pm 0,13\end{array}$ & $\begin{array}{l}6,8 \pm 0,13 \\
7,3 \pm 0,16\end{array}$ & $\begin{array}{l}6,8 \pm 0,30 \\
7,3 \pm 0,07\end{array}$ & $\begin{array}{c}8,1 \pm 0,2 \\
9,6 \pm 0,05\end{array}$ \\
\hline Доношенные/недоношенные & $11 / 12$ & $11 / 9$ & $20 / 20$ & $15 / 5$ \\
\hline Степень недоношенности I/II/III & $8 / 3 / 1$ & $7 / 1 / 1$ & $28 / 8 / 4$ & $4 / 1 / 0$ \\
\hline Степень ЦИ I/II/III & $10 / 7 / 6$ & $10 / 8 / 2$ & $18 / 16 / 6$ & $-/-/-$ \\
\hline
\end{tabular}

дований (клинический и биохимический анализы крови с оценкой уровня кардиоспецифических ферментов: креатинфосфокиназы, лактатдегидрогеназы, уровня тропонина I на автоматическом анализаторе) на 1, 10, 25-27-й день наблюдения. Безопасность препарата оценивали по динамике витальных функций (частота дыхания, сердечных сокращений, температура тела), лабораторных показателей: общий анализ крови (определение гемоглобина, гематокрита, количества эритроцитов, лейкоцитов, тромбоцитов, скорости оседания эритроцитов); биохимический анализ крови (определение общего белка, общего билирубина, креатинина, мочевины, активности АСТ и АЛТ). Катамнестическое наблюдение осуществляли через 3 месяца.

ки развития, перинатальные поражения ЦНС травматического генеза), тяжелой соматической и хирургической патологией (клинически значимые врожденные пороки развития других органов и систем, например гастрошизис, атрезия пищевода, атрезия желчевыводящих путей, некротизирующий энтероколит, муковисцидоз, врожденный гипотиреоз, кишечная непроходимость и др.), с экстремально низкой массой тела при рождении, требующие длительной кардиотонической поддержки или приема антиаритмических препаратов.

Пациенты были рандомизированы на две группы (табл. 1), а исследуемая группа - на 2 подгруппы, сопоставимые по возрасту, сроку гестации, степени ЦИ, характеру и тяжести сопутствующей патологии. Новорожденные основной группы получали дополнительно к стандартным мерам по выхаживанию и лечению (оптимальное вскармливание, респираторная поддержка, коррекция электролитов, инфузионная, антибактериальная и диуретическая терапия по показаниям) 10 внутривенных инфузий препарата L-карнитин с переходом на прием препарата per os в дозе 50 мг/кг/сут в 2 приема до 1 месяца. Препарат, разведенный в 20 мл 5\%-ного раствора глюкозы, вводили внутривенно капельно со скоростью 20 капель в минуту первой подгруппе $(\mathrm{n}=23)$ в дозе 80-100 мг/кг/сут, второй $(\mathrm{n}=20)-50$ мг/кг/сут.

Группу сравнения составили 40 пациентов (доношенные и недоношенные) с постгипоксической кардиопатией, сопоставимые с детьми исследуемой группы по гендерному составу, сроку гестации, характеру основной и сопутствующей патологии. Контрольную группу составили 20 доношенных и недоношенных детей без признаков перинатальной гипоксии и клинически значимого постгипоксического повреждения ЦНС и ССС.

Протокол исследования включал ежедневный осмотр и физикальное обследование в течение 10 дней и анализ результатов инструментальных (ЭКГ и эхокардиография, суточное мониторирование ЭКГ и биохимических иссле-
Статистическую обработку полученных результатов проводили методами вариационной статистики, достоверность оценивали с помощью метода хи-квадрат и t-критерия Стьюдента при 5\%-ном уровне значимости.

\section{РЕЗУЛЬТАТЫ ИССЛЕДОВАНИЯ}

Состояние детей на момент включения в исследование определялось степенью морфо-функциональной незрелости и тяжестью ЦИ. Масса тела детей при рождении в зависимости от гестационного возраста варьировала от 1090 до 3850 г (составив в среднем в исследуемой группе 2483,5 \pm 127,3 г и в группе сравнения - 2500,1 \pm 71,6 г), при этом 45-51,2\% детей в каждой группе родились раньше срока и каждый 8-й ребенок имел задержку внутриутробного развития плода. Около половины детей, включенных в исследование, перенесли хроническую внутриутробную гипоксию, 15-23,2\% - острую асфиксию в родах и 27,9-35\% - их сочетание. 17 (39,5\%) детей исследуемой группы (по 8-9 в каждой подгруппе) и 16 (40\%) группы сравнения находились на зондовом кормлении. В респираторной поддержке нуждались 15-18,6\% детей. У 40-41,8\% новорожденных в каждой группе имела место анемия, у 55,8-60\% - неонатальная желтуха со средними цифрами билирубина 139,83 $\pm 16,3$ мкмоль/л, у 11,6-15\% - инфекции кожи, мягких тканей, мочевыводящих путей.

Нами было подтверждено известное положительное влияние препарата L-карнитин на общесоматический статус детей. В исследуемой группе отмечалась более выраженная динамика прибавки массы тела относительно группы сравнения: $236,0 \pm 23,1$ г против 190,7 \pm 31,9 г за 10 дней и 806,2 \pm 49,1 г против 703,4 \pm 52,1 г за месяц соответственно, $p \leqslant 0,05)$. Анаболический эффект препарата L-карнитин был более выражен у детей, имевших задержку внутриутробного развития. Длительность ИВЛ в исследуемой группе составила 5,3 \pm 0,4 дня против 7,2 \pm 
$0,5$ дня в группе сравнения ( $p \leqslant 0,05)$. K 10-му дню терапии 16 из 21 (76,2\%) недоношенных детей исследуемой группы (11 из которых получали препарат L-карнитин в дозе 80-100 мг/кг/сут), а к 1-му месяцу жизни все недоношенные перешли на самостоятельное питание, тогда как в группе сравнения к 1-му месяцу жизни у 5 недоношенных сохранялось нарушение координации актов глотания и сосания. Положительная динамика неврологического статуса была более наглядной к концу 1-го месяца жизни. В исследуемой группе отмечен значительный регресс синдрома угнетения и мышечной дистонии, тогда как в группе сравнения он сохранялся в 62,5-90\% случаев от исходного уровня.

Чаще всего постгипоксическая дезадаптационная кардиопатия у новорожденных, включенных в исследование, проявлялась признаками неонатальной легочной гипертензии и/или персистированием фетальных коммуникаций (43,5-40\%), а также транзиторной дисфункцией миокарда с дилатацией полостей с нормальной или повышенной сократительной способностью миокарда (34,7-30\%), реже встречались расстройства ритма и проводимости (8,8-10\%). У каждого 10-го ребенка имели место сочетанные нарушения.

В объективном статусе на 2-4-е сутки жизни у новорожденных отмечались различные клинические проявления, сопоставимые в обеих подгруппах исследуемой группы и группе сравнения. Почти у всех детей, находившихся под наблюдением, регистрировались мраморность кожных покровов (86,9-90\%), больше чем у половины регистрировались различные нарушения ритма: тахи-и брадикардия, аритмия, экстрасистолия (50-65\%), а также систолический шум средней интенсивности во 2-3-м межреберье слева от грудины (50-52,2\%). Чуть реже отмечались цианоз носогубного треугольника (35-39,1\%) и приглушенность сердечных тонов (35-43,5\%). Одышка и другие дыхательные нарушения имели место у 20-26,1\%, акцент II тона легочной артерии у $15-16,3 \%$.

\section{Анаболический эффект препарата L-карнитин был более выражен у детей, имевших задержку внутриутробного развития}

В процессе исследования у новорожденных обеих групп отмечалась положительная динамика клинического статуса. Но скорость редукции клинических симптомов была максимальна в группе получавших препарат L-карнитин в дозе 80-100 мг/кг/сут. Уже к концу курса внутривенных инъекций препаратом L-карнитин у новорожденных этой группы статистически значимо реже, чем в группе сравнения, определялись цианоз носогубного треугольника (в 8 случаях из 23 против 32 из 40) и нарушения ритма, особенно брадиаритмия (в 6 случаях из 23 против 20 из 40). После месяца лечения препаратом L-карнитин в обеих подгруппах исследуемой группы зарегистрировано полное купирование дыхательных нарушений и статистически значимое уменьшение представленности другой клинической симптоматики. В груп- пе сравнения также был отмечен регресс симптомов поражения сердечно-сосудистой системы, однако их представленность была в среднем в 1,8-2,4 раза выше, чем в исследуемой. К 3-му месяцу жизни клинических проявлений дезадаптационной кардиопатии в исследуемой группе не наблюдалось, а в группе сравнения они сохранялись у 5-7,5\% новорожденных.

\section{После месяча лечения препаратом L-карнитин в обеих подгруппах исследуемой группы зарегистрировано полное купирование дыхательных нарушений и статистически значимое уменьшение представленности другой клинической симптоматики}

По результатам стандартной ЭКГ синусовая тахикардия с ЧСС 188,6 \pm 4,3 уд/мин выявлялась в 32,6-35\% случаев в исследуемой группе (с сопоставимой представленностью в обеих подгруппах) и группе сравнения, чаще у недоношенных детей, а синусовая брадикардия с ЧСС $87,3 \pm 3,96$ уд/мин в 20-20,9\%, как правило, у доношенных с ЦИ ІІ-ІІІ ст. Резкое отклонение электрической оси сердца вправо определялось у 30,2-35\%, а экстрасистолия - у 9,3-10\% новорожденных, включенных в исследование, с сопоставимой представленностью у детей обеих подгрупп исследуемой группы и группы сравнения. Нарушение проводимости по правой ножке пучка Гиса как следствие перенесенной гипоксии зафиксировано у 22 из 43 (51\%) детей исследуемой группы (по 12-10 в 1-й и 2-й подгруппе) и 18 из 40 (45\%) новорожденных группы сравнения. Удлинение корригированного интервала QT (QTc) свыше 440 мс выявлено у 12 (27,9\%) новорожденных исследуемой группы (у 7 в 1-й подгруппе и у 5 - во второй) и 10 (25\%) детей группы сравнения, при этом существенное замедление этого показателя (свыше 460 Мс), отражающее наличие электрической нестабильности миокарда с высоким риском развития аритмий, имело место у 2 из 43 новорожденных в исследуемой группе и у 2 из 40 в группе сравнения (4,7 и 5\% соответственно). Максимальная продолжительность QTс (565мc) была зафиксирована у недоношенного ребенка с ЦИ ІІ ст., рожденного на сроке гестации 35 недель путем кесарева сечения. Нарушения реполяризации отмечались у 58,160\% детей, включенных в исследование, но типичные ишемические изменения (инверсия зубцов Т, депрессия/ подъем сегмента ST) регистрировались у каждого пятого ребенка (табл. 2).

Уже к 10-му дню лечения в обеих группах отмечалась положительная динамика ЭКГ-показателей. В исследуемой группе у половины детей, имевших исходно признаки перегрузки правых отделов сердца, резкое отклонение электрической оси сердца вправо, блокаду правой ножки пучка Гиса, нарушения реполяризации, ЭКГпроявления постгипоксической кардиопатии исчезли к концу курса лечения, тогда как в группе сравнения подобные эффекты были отмечены только у каждого 10-го ребенка. При этом статистически значимая относи- 
тельно исхода редукция расстройств реполяризации была выявлена только в группе больных, получавших препарат L-карнитин в дозе 80-100 мг/кг/сут. B исследуемой группе у 14 из 27 (51,9\%) больных произошло восстановление синусового ритма с нормальной чСС, тогда как в группе сравнения исчезновение аритмий (синусовой тахи-, брадиаритмии, миграции водителя ритма, экстрасистолии) произошло у 6 из 26 (23,1\%) пациентов. Кроме того, у всех детей, получавших препарат L-карнитин, полностью купировались ишемические нарушения, тогда как в группе сравнения они продолжали регистрироваться (хотя и меньшей выраженности) у 20\% новорожденных. Представленность замедления электрической систолы уменьшилась на 58,3\% от исходного уровня в основной группе и на 20\% - в группе сравнения, однако только у детей, получающих большую дозу препарата L-карнитин, перестало регистрироваться существенное замедление QTC (выше 460 мс).

К 1-му месяцу у 22,5\% детей группы сравнения и у 10\% детей во второй подгруппе исследуемой группы продолжали выявляться синусовая тахикардия, экстрасистолия, признаки перегрузки правых отделов сердца и резкое отклонение ЭОС вправо, ишемические нарушения. Среди пациентов, получавших препарат L-карнитин в дозе 80-100 мг/кг, подобные изменения купировались полностью, регистрировалась лишь блокада правой ножки пучка Гиса (в 8,7\%). Средняя продолжительность интервала QTс и отклонения сегмента ST от изолинии были значимо меньше в первой подгруппе исследуемой группы, чем в группе сравнения (табл. 2) и соответствовали показателям здоровых детей.

Терапевтический эффект препарата L-карнитин сохранялся даже после его отмены. Так, к концу 3-го месяца в группе детей, дополнительно получивших препарат L-карнитин, отмечена нормализация электрофизиологической активности миокарда, полное восстановление чСС, продолжительности интервала QTC и возвращение сегмента ST к изолинии и приближение их к показателям здоровых детей, рожденных от физиологической беременности и родов, тогда как у 7 детей группы сравнения (17,5\%) сохранялись нарушения ритма (тахи- и брадиаритмия, экстрасистолия, у 2 (5\%) - отклонение ЭОС вправо и у 4 (10\%) - умеренное замедление QTc.

По данным ЭхоКГ, выявляемость открытого артериального протока (ОАП) и межпредсердных сообщений (МПС) в раннем неонатальном периоде была одинаково высока у всех детей (95-93\%), причем у недоношенных она достигала 100\%, при этом более чем в половине случаев отмечалось сочетанное функционирование МПС и ОАП. Диаметр МПС у детей колебался в пределах 2,2-5,1 мМ, диаметр ОАП - 1,0-2,6 мм. Право-левый сброс отмечался у 20,9-22,5\% детей и связан с наличием персистирующей ЛГ (ПЛГ) (повышение скорости струи регургитации на трикуспидальном клапане более 25-30 мм рт. ст.). Сочетанная дилатация полостей сердца, в основном правого предсердия и правого желудочка, определялась чаще у недоношенных детей (в 15 из 43 (34,9\%) случаев) в сравнении с доношенными (5 из 40 (12,5\%)). У 25-30,4\% детей функционирующие фетальные коммуникации сочетались со снижением систолической функции левого желудочка (ЛЖ), а у 30-35\% - с ее повышением, отражающим наличие гиперкинетического типа гемодинамики. Нарушение диастолической функции желудочков как более чувствительной к влиянию гипоксии регистрировалось у 70-72,1\% детей. ПлГ несколько чаще определялась у доношенных (13 из 40 - 32,5\%), чем у недоношенных новорожденных (11 из 43 - 25,6\%), однако средний градиент давления на трикуспидальном клапане был существенно выше у недоношенных детей $(37,4 \pm 2,6$ мм рт. ст. против 33,2 \pm 3,4 мм рт. ст. у доношенных) и тесно связан с размерами ОАП и потребностью в респираторной поддержке.

На фоне типичных постнатальных сдвигов системы кровообращения уже через 10 дней лечения признаки ПлГ сохранялись лишь у 2 (8,7\%) детей 1-й подгруппы исследуемой группы, у 4 (20\%) - 2-й подгруппы и 10 (25\%) новорожденных группы сравнения. К концу 1-го месяца

\section{Таблица 2. Динамика некоторых показателей ЭКГ у детей с постгипоксической кардиопатией}

\begin{tabular}{|c|c|c|c|c|c|c|c|c|c|}
\hline \multirow{3}{*}{ Показатель } & \multirow{2}{*}{\multicolumn{3}{|c|}{ Группа сравнения, n= 40}} & \multicolumn{6}{|c|}{ Исследуемая группа, $\mathrm{n}=43$} \\
\hline & & & & \multicolumn{3}{|c|}{$\begin{array}{l}\text { препарат L-карнитин 80-100 мг/кг, } \\
n=23\end{array}$} & \multicolumn{3}{|c|}{$\begin{array}{c}\text { препарат L-карнитин } 50 \text { мг/кг, } \\
\text { n= } 20\end{array}$} \\
\hline & $\begin{array}{c}\text { до } \\
\text { лечения }\end{array}$ & $\begin{array}{c}\text { через } \\
10 \text { дней }\end{array}$ & $\begin{array}{l}\text { через } \\
1 \text { мес. }\end{array}$ & до лечения & $\begin{array}{c}\text { через } \\
10 \text { дней }\end{array}$ & $\begin{array}{l}\text { через } \\
1 \text { мес. }\end{array}$ & $\begin{array}{c}\text { до } \\
\text { лечения }\end{array}$ & $\begin{array}{c}\text { через } \\
10 \text { дней }\end{array}$ & $\begin{array}{l}\text { через } \\
1 \text { мес. }\end{array}$ \\
\hline ЧСС средняя, уд/мин & $136,3 \pm 10,7$ & $135,4 \pm 9,2$ & $133,3 \pm 9,3$ & $137,8 \pm 11,4$ & $132,9 \pm 9,2$ & $130,7 \pm 9,5^{*}$ & $137,2 \pm 10,5$ & $136,4 \pm 11,0$ & $132,6 \pm 10,2^{*}$ \\
\hline Тахи- или брадиаритмия, n (\%) & $22(55 \%)$ & $16(40 \%)$ & $11(27,5 \%)$ & $13(55 \%)$ & $4(17 \%) \#$ & $0(0 \%)^{*}$ & $10(50 \%)$ & $6(30 \%)$ & $1(5 \%)^{*}$ \\
\hline QTс средняя, мс & $410,9 \pm 32,0$ & $408,9 \pm 21,5$ & $405,6 \pm 16,7$ & $412,7 \pm 25,3$ & $386,7 \pm 21,6^{*}$ & $375,3 \pm 15,1^{*}$ & $411,6 \pm 21,4$ & $398,5 \pm 20,9$ & $389,4 \pm 19,7^{*}$ \\
\hline Удлинение интервала QТTc, n (\%) & $10(25 \%)$ & $8(20 \%)$ & $4(10 \%)$ & $7(30,1 \%)$ & $1(4 \%)$ & $0(0 \%)$ & $5(25 \%)$ & $4(20 \%)$ & $2(10 \%)$ \\
\hline ПCO-ST, MM & $0,66 \pm 0,08$ & $0,49 \pm 0,04$ & $0,39 \pm 0,05^{*}$ & $0,69 \pm 0,06$ & $0,35 \pm 0,03^{*} \#$ & $0,17 \pm 0,05^{*} \#$ & $0,67 \pm 0,07$ & $0,42 \pm 0,04^{*}$ & $0,20 \pm 0,03^{*} \#$ \\
\hline Ишемические изменения n (\%) & $8(20 \%)$ & $4(10 \%)$ & $0(0 \%)$ & $5(21,7 \%)$ & $0(0 \%)$ & $0(0 \%)$ & $4(20 \%)$ & $2(10 \%)$ & $0(0 \%)$ \\
\hline
\end{tabular}

* Достоверность отличий от исходных показателей при $p \leqslant 0,05$; \# достоверность отличий от показателей детей группы сравнения при $p \leqslant 0,05$. 


\section{Рисунок 1. Изменения размеров фетальных коммуникаций на фоне терапии}

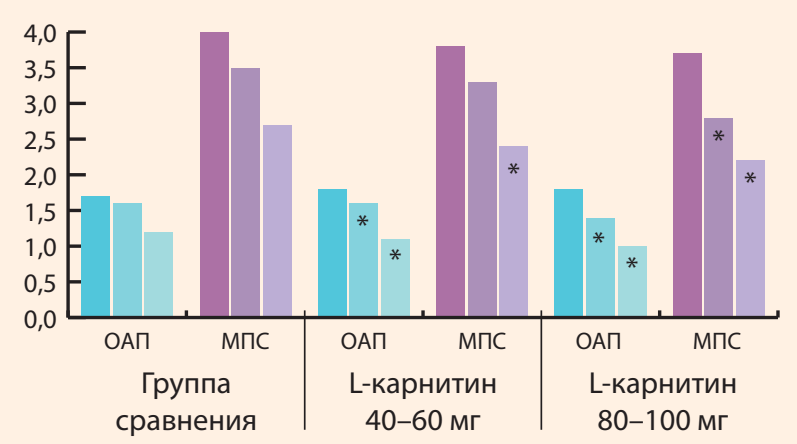

* Достоверность отличий при $p \leqslant 0,05$

жизни ПЛГ продолжала определяться у 5 из 43 (11,6\%) детей исследуемой группы, рожденных раньше срока, и 8 из 40 (20\%) детей в группе сравнения. К 3 месяцам жизни ЛГ была зарегистрирована только в группе сравнения у одного ребенка, рожденного на сроке 33 недели.

Уже к концу неонатального периода у недоношенных детей обеих групп уменьшалось функционирование фетальных коммуникаций (рис. 1). Персистирование ОАП продолжалось у 1 ребенка (2,3\%) исследуемой группы, получавшего препарат L-карнитин в дозе 50 мг/кг/сут, и 4 (10\%) детей группы сравнения против 13 (30,2\%) и 10 (25\%) соответственно. Размеры ОАП уменьшились на $43 \%$ от исходных значений $(p \leqslant 0,05)$ в основной группе (более значимо у детей, лечившихся большей дозой препарата L-карнитин) и на $28 \%$ у детей группы сравнения. Статистически значимое уменьшение встречаемости МПС было зафиксировано лишь к 3 месяцам жизни: в исследуемой группе на 30-34\%, тогда как в группе сравнения - на $12 \%$. При этом значительная положительная динамика размеров МПС у детей, получавших препарат L-карнитин в дозе 80-100 мг/кг/сут, отмечалась уже к 10-му дню лечения и была четко связана с более быстрым регрессом ПЛг.

Проведение стандартной терапии к 1-му месяцу способствовало восстановлению систолической и диастолической функции у 65-42,5\% пациентов. Использование препарата L-карнитин в составе стандартной терапии способствовало статистически значимому увеличению фракции выброса (ФВ) на 9-10\% ( $<<0,05)$ и восстановлению систолической функции ЛЖ у всех детей с ее исходным снижением. Размеры левых камер сердца, исходно увеличенные у 32-67,5\% детей, нормализовались у всех детей, получавших препарат L-карнитин к месяцу жизни, а у детей группы сравнения показатели центральной гемодинамики приближались к показателям практически здоровых детей к 3 месяцам жизни.

По данным суточного мониторирования ЭКГ на 4-6-й день жизни у детей исследуемой и группы сравнения было выявлено статистически значимое повышение среднедневной и минимальной ночной ЧСС, а также продолжительности пауз ритма по сравнению с показателя- ми здоровых детей $(p<0,05)$. При этом у $15-20 \%$ обследованных значения асистолии выходили за границы возрастной нормы, достигая максимально 1220 мс. у $12-33 \%$ детей выявлены различные нарушения ритма и проводимости в виде одиночных, парных, групповых, блокированных экстрасистол, эпизодов миграции водителя ритма, синоатриальной блокады 2-й степени, атриовентрикулярной диссоциации. Их количество не было клинически значимым и ни у одного ребенка не потребовало подключения традиционных противоаритмических препаратов. Среднее значение циркадного индекса (ЦИ), представляющего собой отношение среднедневной к средненочной ЧСС, составило 1,02 $\pm 0,02$ и 1,03 $\pm 0,03$ в исследуемой группе и группе сравнения против $1,16 \pm$ 0,03 у здоровых детей, что свидетельствует о ригидности циркадного ритма и недостаточных адаптационных возможностях системы кровообращения.

Среднедневная, средненочная ЧСС и продолжительность пауз ритма снижалась на всем протяжении исследования. К концу 1 месяца разница с исходными параметрами составила $5,6-9,4 \%(p \leqslant 0,05)$ в 1-й подгруппе исследуемой группы, 2,0-4,3\% - во 2-й подгруппе и 2,6-1,5\% - в группе сравнения. К 3 месяцам динамика по сравнению с исходными данными достигала 12,5-13,7\% и была статистически значима во всех группах, а показатели ЧСС в различные периоды суток не отличались от показателей здоровых детей.

\section{Введение инъекционной формы препарата L-карнитин в план лечения доношенных и недоношенных детей способствует лучшему набору массы тела, более быстрому регрессу неврологических изменений, улучшению дыхательных функций, становлению глотательного и сосательного рефлексов у недоношенных детей}

К месяцу лечения у новорожденных исследуемой группы отмечался статистически значимый рост минимальной чСС на 12-14\% по сравнению с исходными данными, тогда как в группе сравнения подобная динамика была отмечена только к концу 3-го месяца жизни. Максимальная ЧСС снизилась к концу периода новорожденности с $199,9 \pm 9,3$ до 180,5 \pm 7,2 уд/мин $(p \leqslant 0,05)$ в исследуемой группе и с 201,2 \pm 9,4 до 194,3 \pm 12,2 уд/мин ( $1 \geqslant 0,05)$ в группе сравнения. Положительная динамика была особенно заметна у детей, получавших препарат L-карнитин в дозе 80-100 мг/кг/сут: 194,7 \pm 4,8 уд/мин против $182,2 \pm 5,0$ в группе сравнения $(p \leqslant 0,05)$. Средние значения ЦИ у детей, лечившихся препаратом L-карнитин, увеличились к месяцу жизни с 1,02 \pm 0,02 до 1,09 \pm 0,01 $(p \leqslant 0,05)$ (в группе сравнения данный показатель практически не изменился: 1,04 \pm 0,01 против 1,03 \pm 0,03 исходно). Патологические значения циркадного индекса и пауз ритма, как и признаки дисфункции синусового узла, регистрировались значимо реже в исследуемой группе относительно группы сравнения (14\% против 43\%). 


\section{Рисунок 2. Динамика уровня кардиоспецифических ферментов у детей с постгипоксической кардиопатией (в \% от нормы) на фоне лечения}

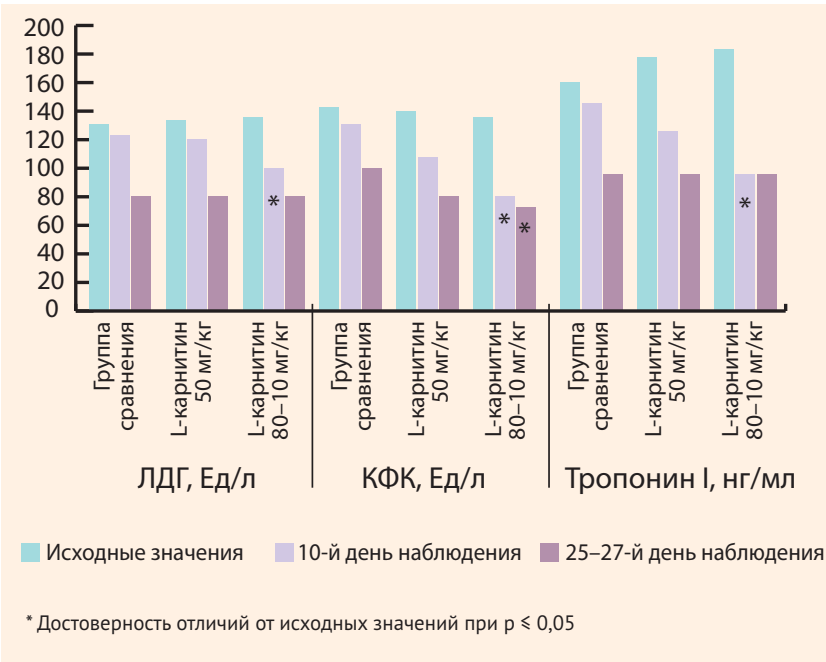

Концентрация кардиоспецифических ферментов превышала референсные значения у 5-45\% детей в каждой группе. Причем наиболее часто (в 39-45\%) определялось повышение уровня креатинфосфокиназы (КФК), реже (5-8\%) - тропонина І. Однако именно последний показатель четко ассоциировался с наличием ишемических изменений ЭКГ. Уровни кардиоспецифических ферментов на фоне терапии достоверно снижались в обеих группах. В исследуемой группе нормализации показателей у абсолютного большинства пациентов удалось добиться уже к 10-му дню лечения, а в группе сравнения - к концу 1-го месяца жизни. Наиболее динамично менялся под влиянием лечения уровень тропонина І. Положительная динамика этого показателя была максимально выражена в группе получавших препарат L-карнитин в дозе 80-100 мг/кг/сут: нормализация отмечалась у всех новорожденных к 10-му дню жизни (рис. 2).

Во время внутривенного введения препарата L-карнитин и после прекращения инфузии не отмечалось нарушения общего самочувствия ребенка. У 3 недоношенных
(6,9\%) детей отмечалось появление срыгиваний до 2 раз в сутки в течение 2 дней, что не потребовало отмены препарата. У 2 новорожденных (1 из них получал препарат в дозе 50 мг/кг/сут и 1 - в дозе 80-100 мг/кг/сут) усилились признаки гипервозбудимости в виде затруднения при засыпании, вздрагиваний, поверхностного сна в течение 2-3 дней, что также не потребовало отмены препарата. Аллергических реакций, нарушений стула, гипертермии, изменения функции жизненно важных органов не отмечено ни у одного ребенка. Значения лабораторных показателей в ходе лечения не претерпевали существенной динамики и не отличались от нормы для данного возраста.

\section{ЗАКЛЮЧЕНИЕ}

Введение инъекционной формы препарата L-карнитин в план лечения доношенных и недоношенных детей способствует лучшему набору массы тела, более быстрому регрессу неврологических изменений, улучшению дыхательных функций, становлению глотательного и сосательного рефлексов у недоношенных детей. Дополнительное назначение L-карнитина внутривенно более эффективно по сравнению с использованием только стандартной схемы лечения, оно способствовало улучшению клинического статуса и оптимизации постнатальной деятельности сердечно-сосудистой системы. Нами отмечены эффективная редукция признаков электрической нестабильности и ишемии миокарда, восстановление чСС и нормализация систолической и диастолической функции сердца, размеров полостей сердца, уменьшение диаметра и гемодинамической значимости функционирующих фетальных коммуникаций, восстановление циркадной организации ритма сердца, а также сокращение длительности пауз ритма и представленности аритмий. Наиболее быстрый и полный регресс проявлений постгипоксической кардиопатии наблюдался при введении препарата в течение 10 дней в дозе до 100 мг/кг/сут и продолжении приема до 1 месяца. Внутривенные инфузии препарата L-карнитин переносились новорожденными удовлетворительно и не сопровождались клинически значимыми побочными эффектами.

\section{ЛИТЕРАТУРА}

1. Здравоохранение в России. 2015: Стат.сб./ Росстат. М., 3-46. 2015. 174 с.

2. Белозеров Ю.М. Детская кардиология. М. МЕДпресс-информ, 2004. 600 с.

3. Котлукова Н.П. Патология новорожденных и детей раннего возраста: лекции по педиатрии. М., 2002. Т. 2: 153-172.

4. Armstrong K, Franklin O, Sweetman D, Molloy EJ. Cardiovascular dysfunction in infants with neonatal encephalopathy. Arch Dis Child, 2012 Apr, 97(4): 372-5.

5. Николаева Е.А., Ледяев М.Я., Ключников С.О. Недостаточность карнитина у детей: причи ны возникновения, профилактика и лечение (пособие для врачей). Российский вест- ник перинатологии и педиатрии, 2008, 2: 35-40.

6. Прахов А.В. Неонатальная кардиология. Н. Новгород: Изд-во Нижегородской государственной медицинской академии, 2008. 388 c

7. Sweetman D, Armstrong K, Murphy JF, Molloy EJ. Cardiac biomarkers in neonatal hypoxic ischaemia. Acta Paediatr, 2012 Apr, 101(4): 33843. doi: 10.1111/j.1651-2227.2011.02539.x. Epub 2011 Dec 23.

8. Ледяев М.Я. Применение препарата Элькар в практике неонатолога. Медицинский вестник, 2007, 4: 12-15.

9. Crill C, Helms RA. The Use of Carnitine in Pediatric Nutrition. Nutrition in Clinical Practice, 2007, 22(2): 204-213.
10. Балыкова Л.А., Гарина С.В, Назарова И.С. и др. Оценка эффективности применения Элькара (L-карнитин) у недоношенных новорожденных. Вестник Мордовского университета, 2016, 26(2): 169-179.

11. Тумаева Т.С., Балыкова Л.А., Пиксайкина О.А. и др. Недоношенные дети, рожденные посредством кесарева сечения: динамика состояния в раннем возрасте при использовании в составе комплексной терапии препарата левокарнитина. Вопросы практической педиатрии, 2016, 11(2): 31-37.

12. Агапитов Л.И., Белозеров Ю.М. Эффективность L-карнитина в коррекции эндотелиальной дисфункции у детей с хроническими бронхолегочными заболеваниями и нарушением легочной гемодинамики. Вопросы практической педиатрии, 2010, 4: 74-77. 